\title{
Comparative Study to Detect Optimum Time for Removal of Urinary Catheter after Hypospadias Repair Surgery
}

\author{
TAREK F.A. KISHK, M.D.*; MOHAMED S. AMMAR, M.D.**; AHMED A. TAALAB, M.D.* and \\ TAREK M.W.E.A. SOROR, M.Sc.* \\ The Departments of Plastic Surgery* and General Surgery**, Faculty of Medicine, Monofia University, Monofia, Egypt
}

\begin{abstract}
Background: Hypospadias is the most common congenital penile anomaly occurring in 1/300 live births. Various surgery techniques are used in repair of hypospadias. Infant and children with hypospadias are usually admitted to emergency services by their worried parents for the first time. TIP urethroplasty is widely used in the repair of hypospadias, but the use of urethral catheters is still a matter for discussion
\end{abstract}

Aim of Work: To determine the optimum time for removal of the urinary catheter after hypospadias repair surgery by comparing three different groups, early (within $24 \mathrm{hrs}$ ), moderate (7-10 days), late (three weeks) removal.

Methods: This randomized controlled study was conducted on 120 patients undergoing hypospadias repair who were divided into three different groups each group comprised 40 patients, the first group catheter was removed within $24 \mathrm{hrs}$, the second group within 7-10 days and the third group within three weeks.

Results: The three groups were matched as regard age, type of hypospadias, associated anomalie, operative time and hospital stay were insignificantly different between three groups, success rate was higher in group B, Complication higher in group $\mathrm{C}$.

Conclusion: Time of removal of the catheter can affect patient discomfort and improve the familiar compliance without increasing acute urinary retention episodes and persistent fistula rate, after TIPU for hypospadias.

Key Words: Hypospadias - Repair - Catheter.

\section{Introduction}

INFANT and children with various genital abnormalities such as interlabial masses, hypospadias and ambiguous genitalia are commonly admitted to emergency departments. Hypospadias is the most common congenital penile anomaly occurring

Correspondence to: Dr. Tarek F.A. Kishk, The Department of Plastic Surgery, Faculty of Medicine, Monofia University, Monofia, Egypt in $1 / 300$ live births. It is defined as an incomplete visualization of the genital tubercle leading to an ectopic opening of the urethra on the ventral aspect of the penis [1]

Hypospadias repair one could state that there are as many techniques and their modifications as there are surgeons who perform hypospadias repair. Various catheters are used in hypospadias repair [2].

Some pediatric urologists prefer not to use urethral stents, to avoid inflicting pain and bladder spasm, others favor using stents for $5 \mathrm{~d}$ to $7 \mathrm{~d}$ to minimize the rate of complications for the patient. Common problems associated with urinary catheters in hypospadias repair are infection, encrustation, catheter blockage, bladder spasm and trauma related to catheter insertion [3].

\section{Patients and Methods}

This randomized controlled study was conducted at monofia university hospital and 6 October insurance Hospital in six months period starting from august 2017 on 120 patients undergoing hypospadias repairs divided into three different groups each group involved 40 patients.

Group 1: The first group catheter was removed within $24 \mathrm{hrs}$ after surgery.

Group 2: The second group within 7-10 days.

Group 3: Third group within three weeks.

Inclusion criteria: Male sex, Age 6 months to 4 years, Distal or glanular type, Midshaft type.

Exclusion criteria: Recurrent Hypospadias. Age $>4$ years. Age $<6$ months. Penoscrotal or perineal type. 
Written informed consent were obtained from all patients who agreed to participate in the trial before study entry.

\section{Methods:}

All patients were subjected to: Detailed history taking, usually from the parents, grandfather or grand-mother; full clinical examination, both general and local. Local examination inspected meatal site, size (wide or narrow), skin around, the urethral plate size (wide or narrow) and presence of scarring, prepuce present or absent and its shape, size of the penis, skin deficiency on ventral aspect of penile shaft and or torsion, presence of penile chordee and rotation, presence of penoscrotal transposition, nature of the urinary stream and other associated local anomalies. All patients underwent general anesthesia.
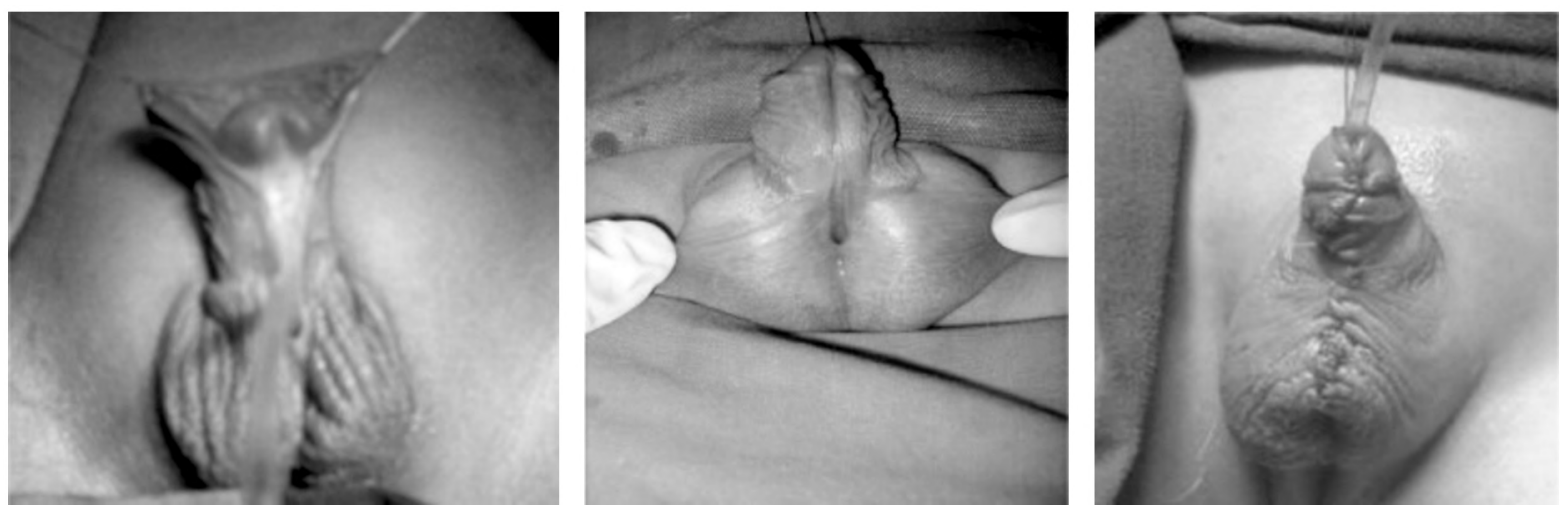

Fig. (1): Assessing surgical outcome.

\section{Visual analog scale:}

Visual analogue scales (VAS) are psychometric response scales used to measure subjective characteristics or attitudes and have been used in the past for a multitude of disorders, as well as in market research and social science investigations, among others.

Statistical analysis: The Data was collected and entered into the personal computer. Statistical analysis were done using Statistical Package for Social Sciences (SPSS/version 17) software.

\section{Results}

In the present study patients in the three groups were matched as regard age, type of hypospadias and accompanied anomaly (Tables 1,2,3).

As regard hospital stay and operative time there was insignificant differences between the three groups with $p$-value $0.987,0.761$ respectively (Table 4, Fig. 2).

Success rate was higher in group B $52.5 \%$ of patients with significant differences between three groups $p$-value 0.040 . Complication rate was higher in group C $75 \%$ of patients with significant differences between three groups ( $p$-value 0.040). Complication in form of fistula which was higher in group A $(52.5 \%)$ with significant differences between three groups $(p$-value $<0.001)$, stenosis higher in group A with significant differences $p$ value $<0.001$, infection rate was higher in group $\mathrm{C}(32.5 \%)$ with insignificant differences between three groups with $p$-value 0.263 , bleeding rate was higher in group A with significant differences between three groups $(p=0.768)$. Bladder spasm and catheter blockage occurred with higher rate in group C (25\%) and (37.5\%) of patients respectively with significant differences between three groups ( $p$-value $0.001,<0.001)$ respectively (Table 5).

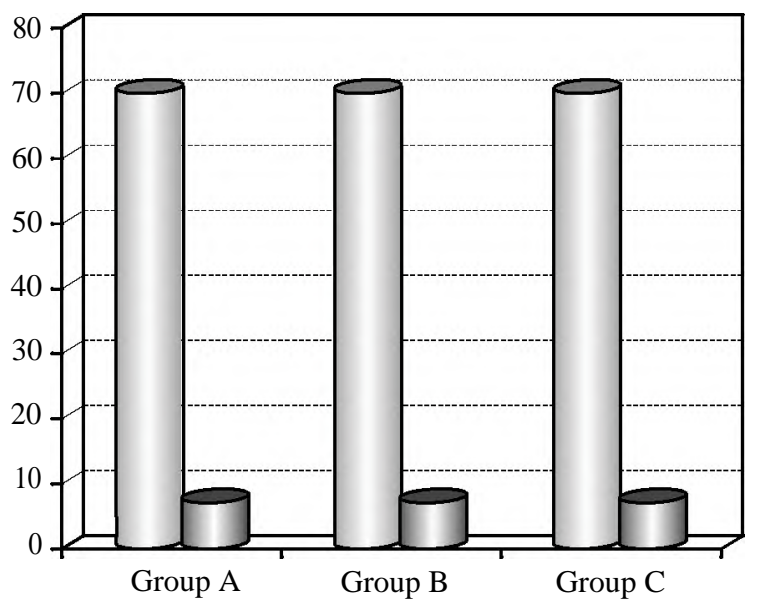

Operative time $\square$ Hospital stay

Fig. (2): Comparison between the different studied groups according to operative time and hospital stay. 
Table (1): Comparison between the different studied groups according to age.

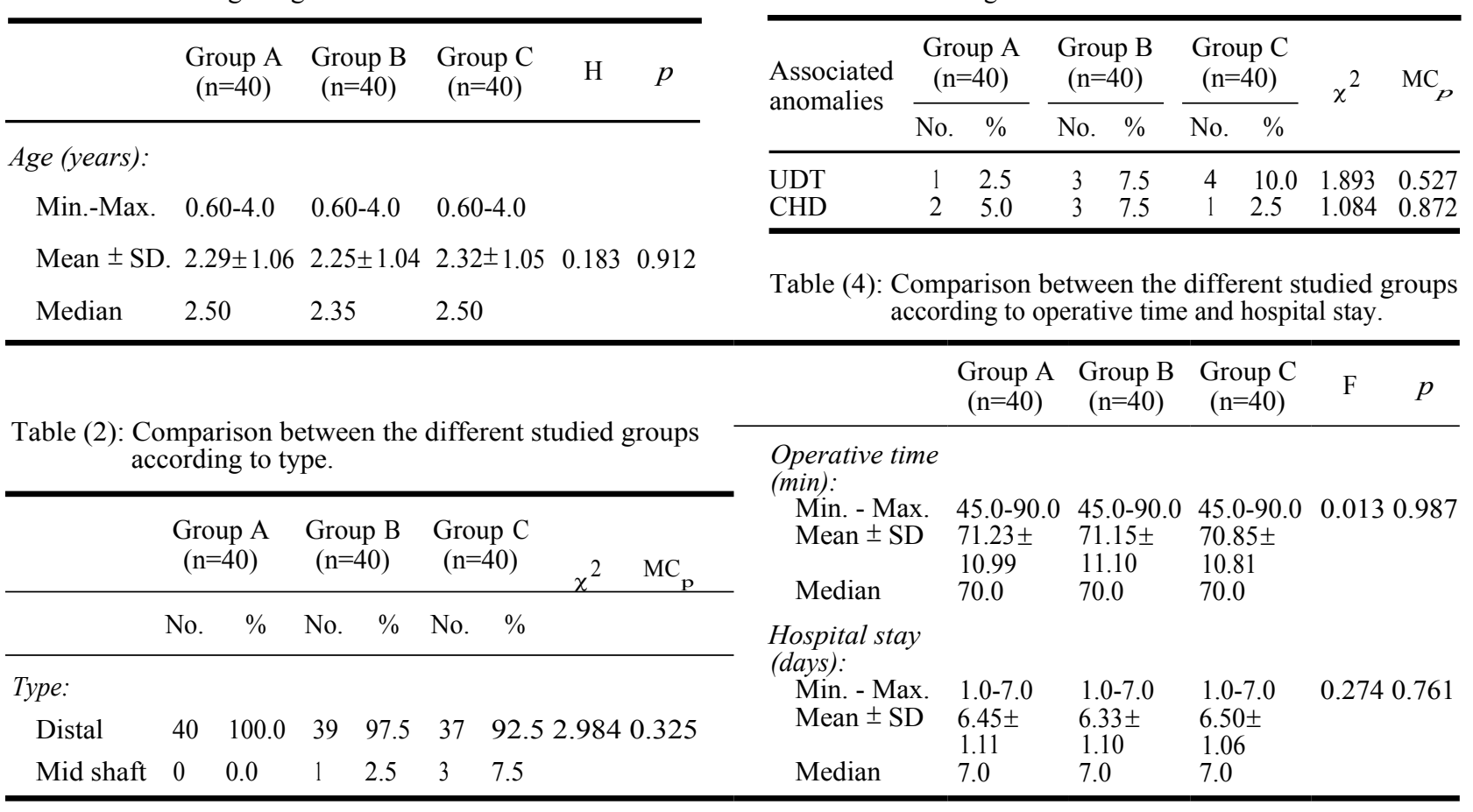

Table (3): Comparison between the different studied groups according to associated anomalies.

\section{.}

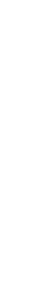


ences between three groups as regard operative time or hospital stay ( $p$-value $0.987,0.761)$ respectively.

In Maria-Grazia study they found that concerning hospital stay, there was a statistically significant difference between the two groups $(p=0.000)$. The median length of hospitalization was 7 days (range 6-9, SD 0.85, CI6.74-7.59) for group A, 3 days (range 3-7, SD 0.94, CI 3.19-3.95) for group B. The mean surgical time was 78 minute in group $\mathrm{A}$ and 81 minute in group B [5].

In the present study we found that success rate was higher in group B $52.5 \%$ of patients with significant differences between three groups ( $p$ value 0.040 ). Complications were higher in group C $75 \%$ of patients with significant differences between three groups ( $p$-value 0.040).

Complication in form of fistula was higher in group A $52.5 \%$ with significant differences between three groups $p$-value $<0.001$, stenosis was higher in group A with significant differences $p$-value $<0.001$, infection was higher in group C $32.5 \%$ with insignificant differences between three groups with $p$-value 0.263 , bleeding was higher in group $B$ with significant differences between three groups 0.768 , bladder spasm and catheter blockage occurred higher in group C $25 \%$ and $37.5 \%$ of patients respectively with significant differences between three groups $p$-value $0.001,<0.001$ respectively.

In Al-Taweel, et al., study they found that the most common complications were fistula, suture line breakdown, wound infection, and stricture formation. In the primary repair group, the success rate was $71 \%(10 / 14)$. The four failed cases were subjected to a second surgery in the form of twostage buccal graft, and the resulting success rate was $100 \%$ (4/4). Patients who presented with secondary hypospadias had a success rate of $55 \%$ $(14 / 26)$ after first surgery. Following a subsequent repair, successful results were achieved in 8 out of 12 repairs. The remaining four patients had a final surgery with only two achieving successes. The overall success rate for adult hypospadias repair was $95 \%$ (38/40) [6]

Maria-Grazia, et al., found that fistula rate was $9 \%(11.1 \%$ in group A, $7.7 \%$ in group B) which is higher but still in the range of what is reported in the literature and similar in the two groups $(2 / 18$ in group A, 2/26 in group B). All the surgeons involved in their study were general paediatric surgeons and had a similar level of expertise. After catheter removal, 3 developed cases of urinary retention (1/18 in group A, 2/26 in group B) which affected toilet trained children older than 24 months [5] (results similar to the one reported by ElSherbiny) [7]

In Shenoy, et al., study they showed that in 14 cases early stent removal was done or no stent was placed and in 16 cases late removal of stent was done. In distal hypospadias cases 2 patients developed fistula and both were from the group in which stents were placed. In proximal hypospadias 6 patients developed fistula post operatively, of these 4 were from the early removal group while 2 were from the late stent removal group [8]

El-Sheribiny et al., studied if stents should be left in toilet trained children after TIP urethroplasty. They concluded that placement of a stent reduces the rate of retention and urinary extravasation in toilet trained children post TIP urethroplasty. In this study there was no difference in fistula rate in toilet trained and untrained children irrespective of the presence or absence of a stent and duration of stent placement [7].

Aslan et al., studied the factors which determine the duration of stent placement post TIP urethroplasty. They found that the patients with short term catheterization had similar outcomes to patients with stents for 7-14 days. Toilet training, position of meatus was not important in determining the duration of stent placement. As far as proximal hypospadias goes there is a general consensus that stent placement is essential in proximal repairs [9]

\section{Conclusion:}

Considering the case series reported in the literature and our preliminary experience, we think that the time of removal of the catheter can affect patient discomfort and improve the familiar compliance without increasing acute urinary retention episodes and persistent fistula rate, after TIPU for hypospadias. By comparing the three groups, we find it advisable to remove the catheter within 710 days after hypospadias repair surgery.

\section{References}

1- KHAN M., MAJEED A., HAYAT W., et al.: Hypospadias repair: A single centre experience. Plast. Surg. Int., 453039, 2014.

2- SUBRAMANIAM R., SPINOIT A.F. and HOEBEKE P.: Hypospadias repair: An overview of the actual techniques. Semin Plast. Surg., 25: 206-12, 2011.

3- POLAT H., YUCEL M.O., CIFT A., et al.: The use of latex foley catheter in repair of hypospadias the most common seen congenital penile anomaly. International Journal of Clinical and Experimental Medicine, 8 (8): 13421-13423, 2015. 
4- JIAO C., WU R., XU X., et al.: Long-term outcome of penile appearance and sexual function after hypospadias repairs: Situation and relation. Int. Urol. Nephrol., 43: 47-54, 2011.

5- MARIA-GRAZIA S., PERIN G., Di GRAZIA M., et al. Surgery for distal hypospadias: What about the catheter? La Pediatria Medica e Chirurgica, [S.1.], V. 39, N. 3, Sep. ISSN 2420-7748, 2017.

6- AL-TAWEEL W.M. and SEYAM R.M. Hypospadias repair during adulthood: Case series. Urology Annals, 9 (4): 366-371, 2017.
7- EL-SHERBINY M.T.: Tubularised incised plate repair of distal hypospadias in toilet trained children: Should a stent be left? BJU lnt., 92(9):1003-5, 2003.

8- SHENOY N.S., KUMBHAR V.V., SHENOY Y.R., et al.: Outcome of hypospadias repair stentless versus stented repair. Int. Surg. J., 3: 2167-72, 2016.

9- ASLAN A.R., YUCEBAS E., TEKIN A., et al.: Short term catheterization after TIP repair in distal hypospadias: Who are the best candidates? Pediatr. Surg. Int., 23 (3): 265-9, 2007.

\section{دراسة مقارنة لتحديد التوقيت الأمثل لرفع القسطرة البولية ما بعد جراحة ليحلة إصلاح الاحليل السملفلى السفلى}

في هذه الدراسة نحن نهدف إلى تحديد الوقت الأمثل لإزالة القسطرة البولية بعد جراحة إصلاح الاحليل السفلى تمت الدراسة على .

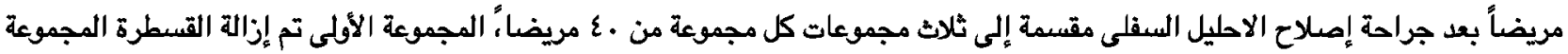

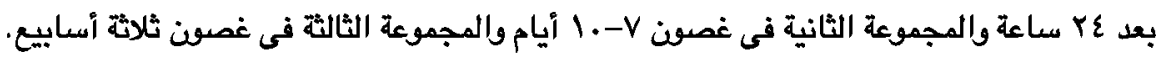

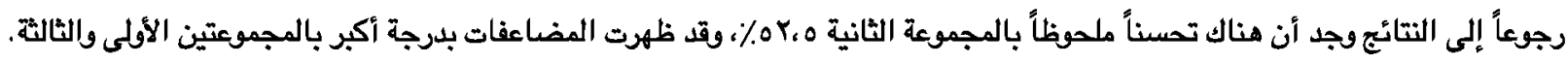

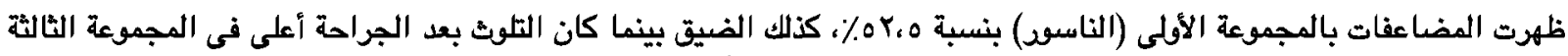


بمقارنة الثلاث مجموعات نجد أنه من المستحسن ازالة القسطرة في غضسن V-1 أيام بعد اجراء جراحة إصلاح الاحليل السفلى. 